\title{
Human Behavior and Environmental Sustainability: promoting a pro-environmental behavior by harnessing the social, psychological and physical influences of the built environment
}

\author{
Shaden Abusafieh \\ Maiss Razem
}

\author{
archshaden@yahoo.com \\ maissrazem@hotmail.com
}

Al-Ahliyya Amman University

Amman-Jordan-Zip-Code (19328)

Phone $+96253500211 \quad$ Mobile +9620787641111
Amman, Jordan

Amman, Jordan

Fax +96265333315

Recently, technological advancements in the sustainable design field have allowed us to reduce the ecological impact of the built environment, to reduce consumption of non-renewable resources, to create healthy environments and in some cases may even rehabilitate the ecosystem. Nevertheless, several studies have been carried out showing that sustainable technology does not automatically lead to environmentally friendly behaviors in its users.

Various environmental problems threaten environmental sustainability and many of these problems are rooted in human behavior. Unfortunately, there is a lack in studies which take into consideration the human behavior influences within a sustainable built environment. We believe that the built environment should be used to support human goals and requirements, but at the same time we should consider it as a context in which human values and behaviors are cultivated.

This research aimed to help in promoting environmental sustainability by using architectural design in changing relevant human behavior toward an environmentally friendly behavior. In order to achieve this, the research adopted Environment-centered Approach to gain more acute perspective into the relationship between the physical environment and human behavior, focusing on social, psychological and physical influences of the built environment.

It appears that environmental psychology's merits have high potential in changing behavior within the built environment. The research provides a systematic approach for selecting, assessing, evaluating the behaviors to be changed and the factors that determine them. 
Furthermore, this approach helps in choosing the best interventions that could be applied in built environment to encourage such a sustainable behavior.

This study tried to construct an agenda for further researches to find particular architectural design elements and strategies that we can harness to develop a pro-environment human behavior.

\section{Introduction}

Environmental psychology is the study of transactions between individuals and their physical settings (Gifford, 2007). It is the branch of Psychology concerned with providing a systematic account of the relationship between a person and the environment (Russell \& Snodgrass, 1987).

For many decades, Environmental Psychologists have tried to study the relationship between environment settings and human behavior as well as how they affect one another. Why are some spaces comfortable and others not? How can we promote our environments to reduce stress, create more efficiency spaces and minimize losses in emergency cases? These are some concerns that environmental psychologists and designers as well have been working with for many decades. Recently, many researches in this field start considering the psychological aspect of sustainability trying to answer the question: Can the built environment enhance and promote a sustainable behavior?

Environmental psychologists rely on many theoretical approaches. Most psychologists examine the effects of environmental stimuli on human perception and responses in one way or another. Ittelson addressed in his note the transactional theory framework "Man is never encountered independent of the situation through which he acts, nor is the environment ever encountered independent of the encountering individual." (Ittelson, 1973). In order to predict a human behavior, transactional perspective to human-environmental relations requires that we study equally people, their perceptions, intentions, purposes and the physical settings in which they transact. 


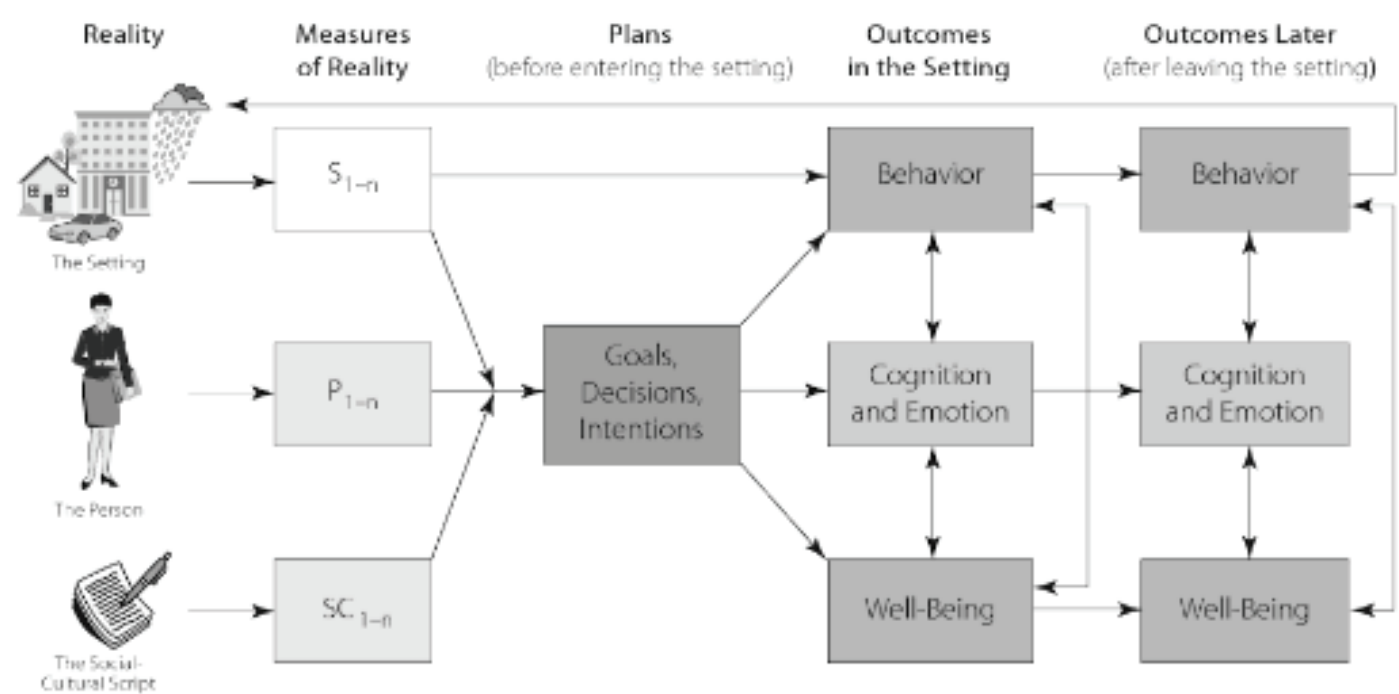

Figure1. An overview of environmental psychology's scope (Gifford, 2007)

\section{Theoretical Bases}

Over the past three decades, researchers who focus on person-environmentbehavior relations conclude that they cannot simply assess people or the environment (Altman, 1975; Churchman, 2002). In classical and environmental centered theories, people are assumed to make rational decisions while performing in their built environments. We all know that people are not always rational about decision making. "Humans rarely choose things in absolute terms. We don't have an internal value meter that tells us how much things are worth" (Dan Ariely, 2010). So, we cannot assume that for example a sustainable well designed built environment will drive the users to have sustainable behaviors as well.

In this research we will adopt the transactional theory which applies equal consideration to human behavior and the settings they transact with on their daily life. Transaction more clearly exemplifies the nature of person-environmentbehavior by considering people and environment inclusive and one defines the other, rather than dealing with them as separate entities. The goal of this research is to provide a theoretical framework that allows designers to understand the humanenvironment dynamics helping them in decision making in constructing a better environment that help in promoting pro-environmental behaviors for users. 


\section{Changing the habit by changing the setting}

There are various environmental problems that threaten sustainability. Many of these problems such as air pollution, water shortages, environmental noise, and littering are rooted in human behavior (Gardner \& Stern, 2002). That means in order to attempt environmental quality improvement we should change relevant behaviour so as to reduce its environmental impacts. For example, sustainable built environment apply physical and technical innovations to gain energy efficiency. But at the same time, individuals need to accept and understand them, buy them, and use them in proper ways. Fortunately, there's a belief that buildings can change behavior. What makes people change their behavior through interaction with their environment which they perceive? To answer this question we will follow Geller (2002) in his method of choosing the right behavior that we should change to pro-environmental behavior that harms the environment as little as possible or even benefits the environment. Behavior change for better is more effective when one (1) selects the appropriate behaviors to be changed in order to promote environmental quality and human quality of life, (2) examines which factors cause those behaviors, (3) applies the best interventions in built environment to change relevant behaviors, (4) Evaluates effectiveness of the interventions (Geller, 2002; Steg \& Vlek, 2009). In many countries, about half of total household energy use is direct energy use (use of electricity, natural gas and other fossil fuels); the other half is indirect energy use (the energy used in the production, transportation and disposal of goods and services). This research will focus on analyzing a case study of a house in Amman-Jordan along with examining some factors influencing household direct energy use, attempting to promote household energy conservation.

\section{Factors that influence decisions that encourage pro-environmental action}

Many theories have studied which factors promote or inhibit pro-environmental behavior. We have to reveal these factors in order to decide which should be chosen to encourage sustainable behaviors. The Theory of Planned Behavior assumes that individuals choose alternatives with highest benefits against lowest costs (TPB; Ajzen, 1991). This approach proposes that attitudes, social norms and perceived behavioral control, together shape an individual's behavior. The TPB was successful in explaining various types of environmental behavior such as household recycling, waste composting, water use and general pro-environmental behavior (Heath \& Gifford, 2002). The norm-activation model (NAM; Schwartz, 1977 ) and the value-belief-norm theory (VBN theory; Stern, 2000) assume that 
people act pro-environmentally when they feel a moral obligation to do so. In order to activate sustainable personal norms for behavior, they suggest different variables from values and general environmental concern to which people are aware of negative consequences of certain actions and their ability and responsibility to avoid these negative consequences. The NAM and VBN theories have been successful in explaining low-cost environmental behavior and good intentions such as willingness to change behavior.

Recently, behavioral economics have become a credible field that integrates behavioral psychology and the environment in order to improve models of decision-making. There are many great readings in this field such as: Predictably Irrational, Nudge, and Thinking, Fast and Slow. Deriving from behavioral economics, we can follow two routes to achieve changes. First, by changing minds we can directly change behaviors and habits. Second, we can change the decision making by changing the architectural context. Although we can evaluate our options that change our behaviors, our subconscious usually guides our choices. Our decision making do not always relay on objective rational choices, they rather usually come from emotions and irrational thinking (Dan Ariely, 2010). Based on this fact, how can we promote people decision making when it comes to their impact on the environment? Richard Thaler, the author of Nudge, argues "the solution is to apply the single most useful bit of psychology one can ever learn: If you want to encourage people to do something, make it easy - or even better, automatic". Nudge is a collective term for different policy tools that can be used in order to influence individuals' behavior. Table 1 summaries different policy tools and on how they influence the choice of individuals (House of Lords, 2011).

\section{Interventions to promote pro-environmental behavior}

Pro-environmental energy behaviors have been studied from different theoretical perspectives. And many motivational factors proved to be related to specific energy behaviors. In this research we will focus on three types of motivations that are considered behavioral economic concepts influence "via nudges": Salience (as a physical influence), Social norms (as a social influence) and Defaults (as a psychological influence), and how they impact the direct energy use. Nudges are ways of changing the context in which we make decisions to potentially reach different outcomes, while not limiting consumer choice (Richard Thaler, 2009). 
We can use these concepts to create interventions that promote pro-environmental behavior (energy conservation as a case study).

Table 1. Policy tools to influence individual behavior (House of Lords, 2011)

\begin{tabular}{|c|c|c|c|c|c|c|c|}
\hline \multirow{3}{*}{$\begin{array}{l}\begin{array}{l}\text { Regulation of } \\
\text { the individual } \\
\text { Eliminate and } \\
\text { restrict choice }\end{array} \\
\end{array}$} & \multicolumn{2}{|c|}{$\begin{array}{l}\text { Fiscal measures directed } \\
\text { at the individual }\end{array}$} & \multicolumn{5}{|c|}{$\begin{array}{l}\text { Non-regulatory and non-fiscal measures with } \\
\text { relation to the individual }\end{array}$} \\
\hline & \multicolumn{7}{|c|}{ Guide and enable choice } \\
\hline & \multicolumn{3}{|c|}{ Incentives and information } & \multicolumn{4}{|l|}{ Nudging } \\
\hline $\begin{array}{l}\text { Laws and } \\
\text { regulations }\end{array}$ & 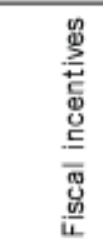 & 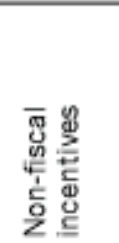 & 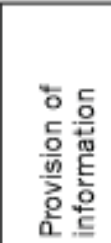 & 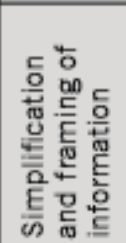 & 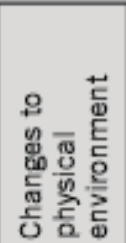 & 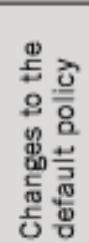 & 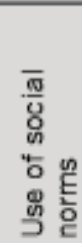 \\
\hline
\end{tabular}

\section{Salience (physical influence)}

Salience is an external process for individuals. The information that stands out and seems relevant has more effect on our thinking and actions (Dolan et al., 2010). Salience guides the judgments that are based on external cues, in other words it simplifies our decision making. According to behavior economics, most of people choices are not the result of careful deliberation. Our thinking is subject to insufficient knowledge, uncertainty feedback, and the context in which we make decisions. For instance, when people assess the energy use of household appliances, they tend to rely on a simple heuristic: The larger the appliance, the more energy it is believed to use and which is not always accurate (Schuitema and Steg, 2005).

We are affected by legible available information, feedback, influences of the context, and salient information in the environment. For example, meter readings reflect how much electricity has been used by a particular household. However, meter readings do not reveal which specific behaviors contributed most to total energy use (heater, oven, refrigerator, ex...). This is consider a problematic for people, that they do not know which and whose behaviors significantly affect energy use, and that they cannot receive specific feedback on the results of their behavioral changes (Gatersleben et al., 2002). Also, we can manipulate salience by 
rearranging the physical environment; for instance, "I want to climb the stair to fitness" sign at Bugis MRT station in Singapore prompts people to take the stairs rather than the escalator. An essential finding in behavioral science is to make it easy for people to choose the preferred option rather than to force them. So, a lightfilled staircase can attract people to use it more since people are naturally drawn to light.

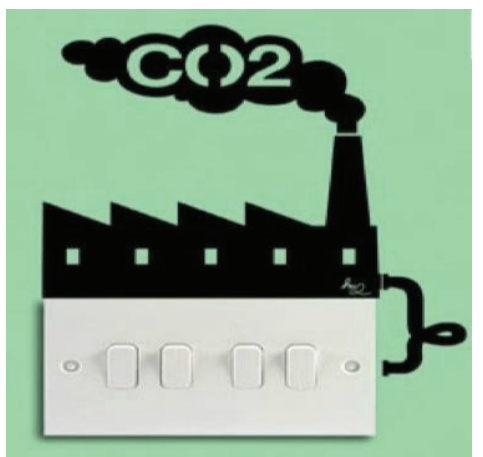

Figure 2. Household reminder of the bigger picture when it comes to

flipping a switch.

Reference:http://blog.sustainability.c olostate.edu/?q=node/59http://blog.s ustainability.colostate.edu

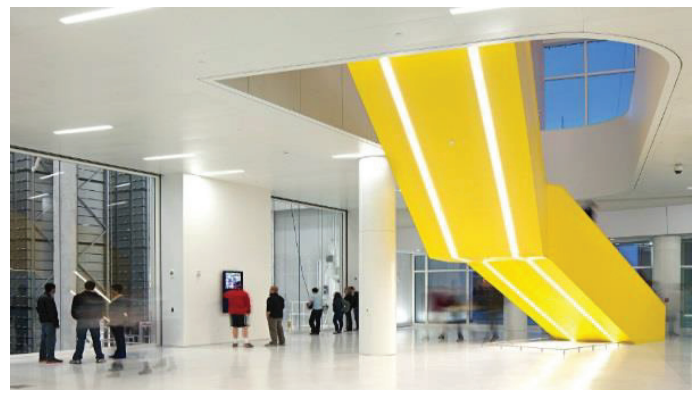

Figure 4: Yellow stairs in the North Carolina University Library placed along the main circulation lines. Reference:

https://sourceable.net/promptingsustainable-behaviour/

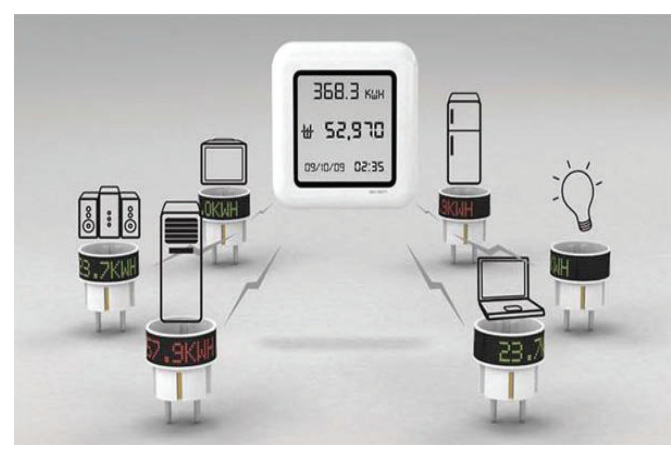

Figure 3. The Diet Watt monitor shows the electrical usage readings in real.

Reference:

http://www.ubergizmo.com/2010/01/d iet-watt-to-help-you-monitor-powerusage/

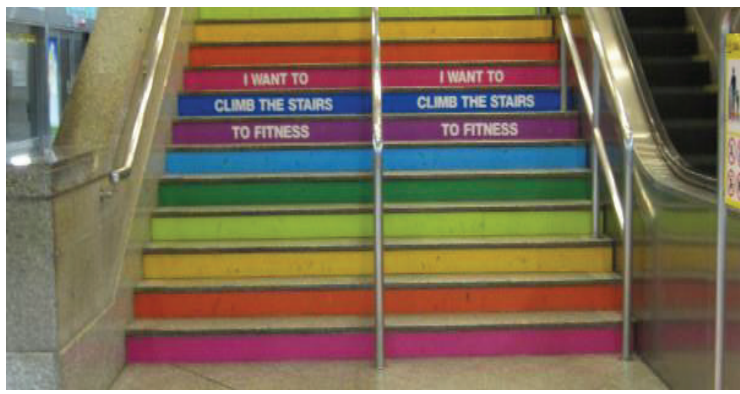

Figure 5: Bugis MRT station, Singapore. Reference: http://inudgeyou.com/archives/780 


\section{Social norms (social influence)}

Environmental concerns and social norms are important in promoting energy conservation behavior, because they provide the most solid basis for it (Lindenberg and Steg, 2007). When energy pro-environmental behavior results from normative concerns, it will be sturdier against changes. Furthermore, some strategies are based on the assumption that positive or negative consequences will influence behavioral choices, so pro-environmental behavior will become a more attractive alternative when positive consequences are attached to it.

Social norms are a strong force that influences human behavior. There are two ways in which social norms affect individuals, as injunctive norms and as descriptive norms. The injunctive norms act as a moral implication (what should be done and what should not to be done). The descriptive norms refer to the simple observation of how most others behave, which will help an individual to choose the best action when he or she is in an uncertain situation (Cialdini et al., 1990). A relevant study found that hotel guests re-used towels more frequently when they were provided with information that emphasized descriptive social norms in favor of re-use ('did you know $75 \%$ of our guests help save the environment by reusing their towels') compared to when they were given environmental information only ('help save the environment by re-using your towels') (Goldstein, Cialdini, \& Griskevicius, 2008). Another research finds that when the company OPower shows how much energy a household is using compared to similar neighbors, a significant impact on changing household energy use was noticed. The households reduced energy use in the short long run (Allcott, 2011).

\section{Defaults (psychological influence)}

According to psychologists, people tend in their behavior to go along with the default options that make life easier. So, can we make the default setting in a way that users will choose the behavior we would prefer to perform? Thaler said: "By paternalism, all we mean is caring about peoples' outcomes. We want to devise policies that will make people better off, not worse off, as judged by them". He added: "we can help people make choices that they themselves think are better" (Thaler, 2008). This goal can be achieved with "choice architecture" which refer to the influence that architects can do so people may change their decision making. 
Default is one of the key features of "architecture choice". Whatever you choose as a default, it will have a better chance to be selected. We need to nudge people toward the right choices hoping to create better and easier lives. For example, Placing staircases directly in obvious spaces and hiding elevators to the side as well as designing interesting and cheerful landings, will highlight the staircases as a default choice. Accordingly, this will encourage a pro-environmental behavior and people will tend to use the stairs more than elevators.

\section{Effectiveness Evaluation of the interventions}

In this research, we aimed to evaluate interventions based on the three nudges concepts: Salience, Default and Social norms by analyzing a case study of a greenhouse located in Amman, Jordan. We tried to reveal the effectiveness of a combination of design interventions on energy conservation behavior. Effectiveness measurements should focus on changing of energy use behaviors and changing in the people's quality of life, as well as people's commitment and their maintain of these changes.

\section{Al-Kamaliya Residence - Environmental Aspects}

Al-Kamaliya residence chosen for this study is considered a green home for its environmentally friendly features. It won the Green Apple Award. The owner of the residence is Dr. Ayoub Abu Dayyeh who also designed and constructed the house, as he is an energy consultant and an active environmentalist. The residence was built in 2009 and is occupied by himself, his wife and his daughter intermittently; three days a week, while they stay at another home closer to the city center the rest of the week. An informal interview was conducted between the authors and Dr. Aby Dayyeh and his wife. The questions during the interview addressed the level of contentment and consequent behavioral change between the occupants and their green home, as they revealed how the design of the house influenced the occupants with varying satisfaction levels from Dr. Abu Dayyeh to his wife.

The house has integrated Solar thermal, P.V solar cells, geothermal energy, rain water harvesting, unique thermal design and passive architectural design to produce a zero carbon emission house at a feasible economical cost. The construction took two years and finished in 2009. During that period all material waste produced on site was reused in an eco-friendly modes within the site and all trees displaced by the construction were successfully replanted. A dry garden was 
established too that needs no irrigation and a wild garden was confined to allow for indigenous plants and wild life to prosper. The house is not heated by fossil fuels nor does it use HVAC. Indoor temperature ranges between 21 to 19 degrees in summer and winter. In January of 2015, the family only needed one electric directheat-source to be operated during the winter time for one day, when the indoor temperature fell below 18 degrees Celsius.

Due to the cold winds of Amman, the western façade was completely closed off as seen in figure.6, while the southern elevation has the largest percentage of windows that allow winter solar rays to heat the indoor space as they block the hot summer radiation to enter with the help of sun-breakers which is illustrated in figure.7. Fewer areas of windows exist in the east and north facades as shown by figure.8. The southern living room has two fixed large double glazed windows, while upper floor spaces have operable and fixed windows. It is uncommon in Jordanian homes to incorporate fixed windows, and the impact of the placement of such windows at Al-Kamaliya house was highly noticeable when we held the interview inside. It was a windy day accompanied by noisy sounds that we could hardly hear each other outside, but as we entered the house all the cold, air movement and sound were cut off; a truly thermally and sound insulated home with veritable air sealing. Because Al-Kamaliya house has no mechanical air circulation, the operable windows induce air flow when prompted by the beep of the $\mathrm{CO} 2$ level reader device if concentrations exceeded $1000 \mathrm{ppm}$.

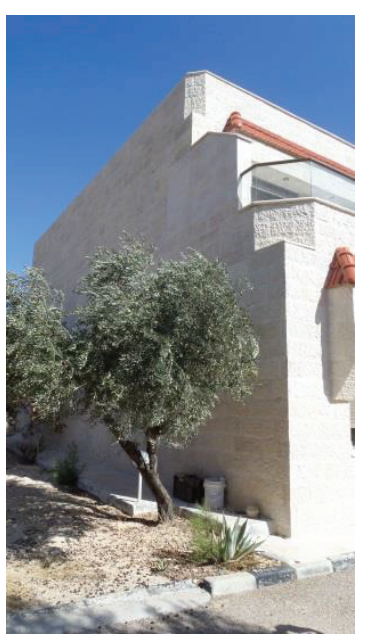

Figure6. Western elevation, Al-Kamaliya house Reference: Researchers

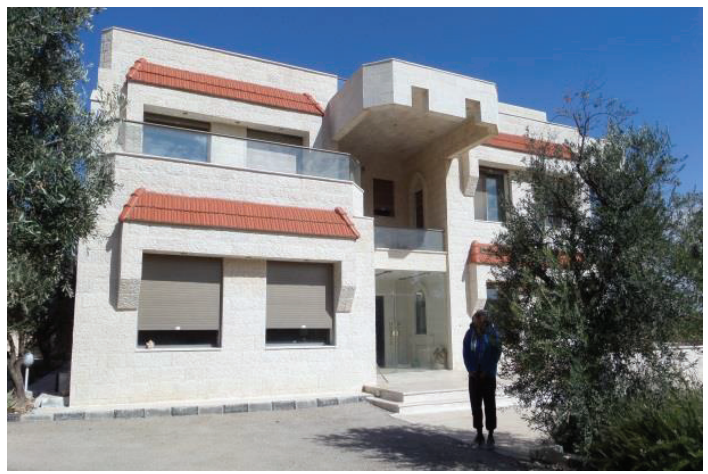

Figure7. Southern elevation, AlKamaliya house Reference: Researchers

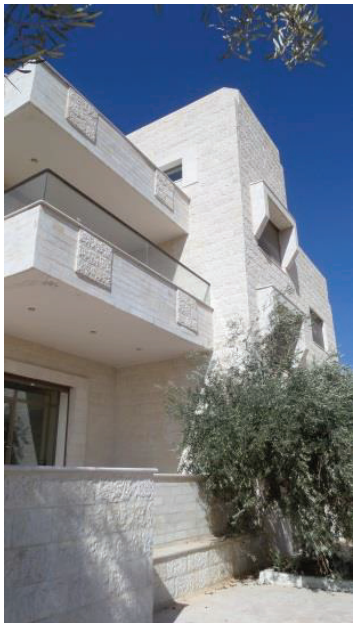

Figure8. Eastern elevation, AlKamaliya house Reference: Researchers 
As the house clearly exhibits careful design and implementation of green technologies, the study aimed to gain more acute perspective into the relationship between the physical environment and human behavior, focusing on social, psychological and physical influences of the built environment. In an informally structured interview, Dr. Abu Dayyeh was asked whether Al-Kamaliya house instigated pro-environmental behaviors in this house and his other home in central Amman for himself and his family.

\section{Physical Influences "Salience"}

Pro-environmental behaviors should be convenient, directly beneficial, and easy to implement in order for them to be effective and sustainable in the long-term. However, the main drawback with environmental enthusiasts' mission is resorting to spreading awareness as the only and most effective means to solve imminent problems. From the various studies conducted by social environmental psychologists and behavioral economists to produce influential outcomes in behavioral change, the most effective approach is to change the social context and driving norms.

As seen in figure.9, signage and environmental paintings were hung on the house's walls which represent a medium of educating the home occupants and constant messaging of the unique nature of the house that activates conscious awareness to maintain their pro-environmental behaviors. These types of Informational strategies are influential when pro-environmental behavior is relatively convenient and economical (Steg and Vlek, 2009).

Another Salience strategy that instigated pro-environmental behavior, and that led to turning off lights when not used and so reducing electricity consumption, is the installation of the electricity consumption reading meter (OWL meter) figure.10. Mrs. Yasmeen after a while started closely following the home's consumption and the active reading on the meter as a daily behavior. The family is attentively engaged with the meter's feedback and their energy saving behavior becomes more instilled. This salience strategy values information feedback especially when it is visually represented using recent technologies in the design of homes, geared towards changing behaviors. It shows that the more specific, personalized, and beneficial the normative information the better desired behavioral change is achieved. 


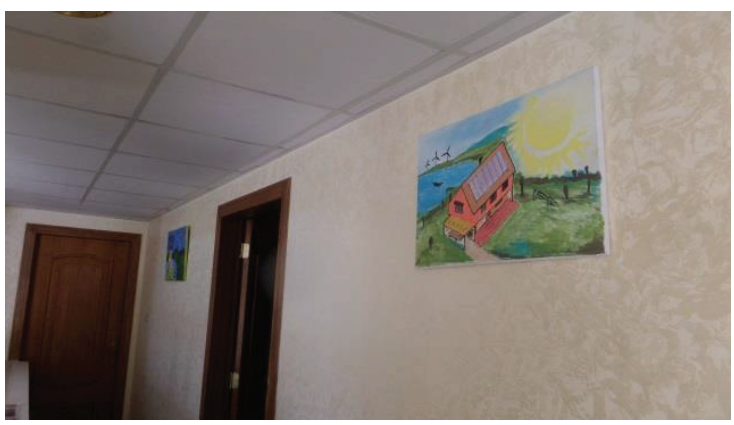

Figure9. Environmental paintings, Al-Kamaliya house Reference: Researchers

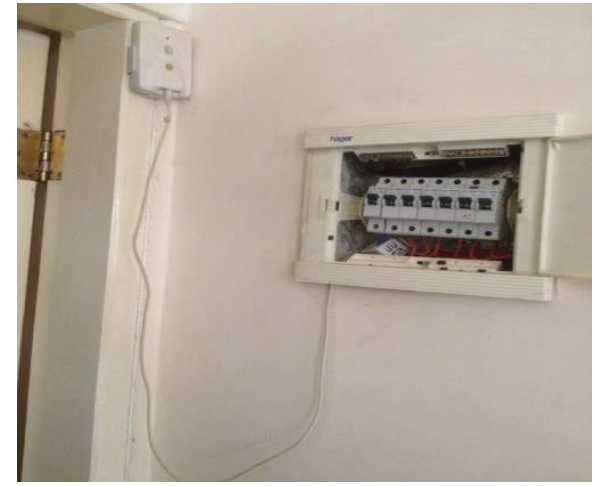

Figure10. OWL meter, Al-Kamaliya house

Reference: Researchers

\section{Social Influences "Social norms"}

The more people engage in a certain behavior the more the individual follows suit with the group's behavior by following social norms inducted by either unwritten cultural rules, or by policies. Within the confines of the home, the occupants themselves serve as a social group for its individual members to emulate. Such is the role of the informed homeowner whose aim is to reduce the energy bills and is thus incentivized to behave sustainably. The OWL meter, for example, introduced a new social norm in the household that engaged every occupant to monitor and reduce electricity consumption.

A larger social influence of Al-Kamaliya house was when it won the Green Apple Award and was publicized in the media channels. The transfer of the best practice attracted clients who wanted to build a green home. Here, a potent social norm of building green is at play, where telling people about the actual achievements of AlKamaliya's environmental benefits and economic feasibility has attracted interested individuals. Depending on measured green homes' viability and regardless of regulations that might drive a pro-environmental behavior, the impact of the social norm is likely to be more profound. 


\section{Psychological Influences "Default concept"}

Many windows are designed as fixed to maintain thermal comfort. According to Dr. Abu Dayyeh, the need to open windows all the time and maintain air flow is inefficient when a controlled indoor thermal comfort is to be achieved, thus he decided to minimize operable windows The Fixed windows was a default feature inside the house figure.11. In their other home in Amman, which consists of operable windows, the behavior of Mrs. Yasmeen and her daughter seemed to have altered a bit in a reduced urge to open the windows. This behavior change must have been instigated by Al-Kamaliya house. That they realized added benefits of keeping the indoor thermal comfort within range, classically exhibiting the case of how a changed context can produce new habits. It is worth mentioning here that 'opening windows for ventilation' even at winter time to introduce fresh Oxygen, sometimes longer than needed, seems to be a behavioral pattern among ladies of Jordanian households, becoming a social cultural norm.

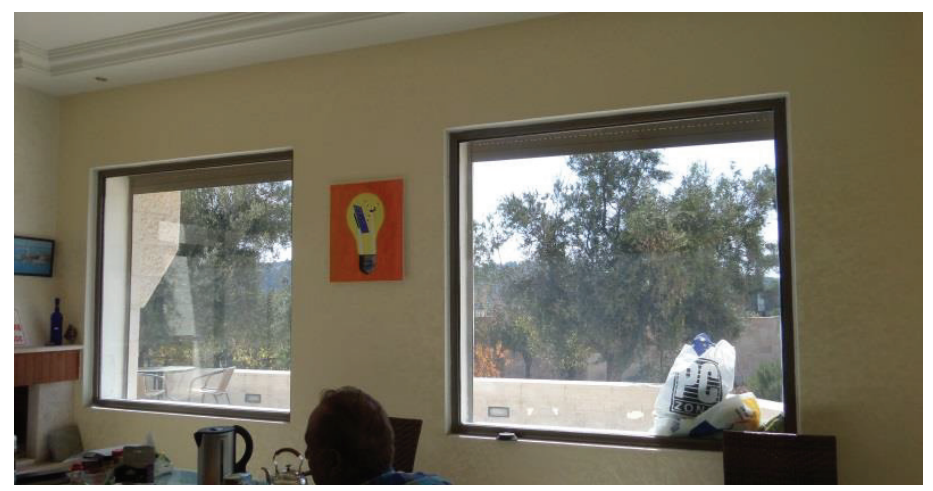

Figure11. Fixed windows as a default feature Reference: Researchers

\section{Conclusion}

Social Psychologist Daryl Bem once observed that an attitude requires a "fact, a feeling, and a following". It is paramount to comprehend and incorporate the full spectrum of the various users' attitudes and behaviors when designing a green building, more so homes. Human behaviors are as complex factors in design as the technical accomplishment of environmentally friendly features, granting the 
integrative design process more potency when pro-environmental behaviors are to be nurtured sustainably from factual, emotional and social aspects.

Nudges coming from different concepts such as salience, social norms and default have an important role to play in promoting energy conservation via behavioral changes. Environmental interventions are generally more effective when they are systematically planned, implemented and evaluated in order to choose the best behavior to be changed. This can be achieve by going through the four steps addressed in this research:

To achieve and to maintain environmental sustainability, individuals can contribute significantly by promoting sustainable behaviors that can reduce household energy use. The challenge for Architects is to understand the individual, factors that influence their behaviors and the processes of choosing architectural choices that create pro-environmental behaviors.

Further research may be conducted to further improve intervention studies by considering energy conservation from an interdisciplinary perspective. For instance, according to the ventilation issue, a question arises here whether opening windows for ventilation is an exaggerated and unwarranted behavior in our culture. Such inquiry indeed heralds further research to include a better informed holistic understanding instead of following a reductionist reasoning. What activates the behavior of ventilation; social norms, habits, individual attitude, or physiological needs? Who is most motivated by which behavior driver in a typical household? Moreover, can aesthetic taste hinder sustainable behaviors if the market does not afford environmentally aesthetic choices? Therefore, more studies should focus more on attitudes, emotions as well as cognitive so we can understand humans and control their behaviors in different context. To elucidate the power of affect in driving behaviors, T. Heberlein concludes in his book 'Navigating Environmental Attitudes' that: "We often forget that attitudes have two parts, the cognitive and the emotional, and too often research focuses on the cognitive. The real power of attitudes is the emotional dimension." 


\section{References}

Altman, I. (1975). The environment and social behavior: Privacy, personal space, territoriality, and crowding. Monterey, CA: Brooks/Cole.

Altman, I., \& Rogoff, B. (1987). World views in psychology and environmental psychology: Trait, interactional, organismic and transactional perspectives. In I. Altman \& D. Stokols (Eds.), Handbook of environmental psychology. pp. 245-281, New York: Wiley.

Ariely, Dan. (2010). Predictably Irrational: The Hidden Forces That Shape Our Decisions. Harper Collins. A well written introduction to the implicit influences on our behaviour by one of the leading behavioural economists.

Bechtel, R. B., \& Churchman, A. (Eds.). (2002). Handbook of environmental psychology. New York: Wiley.

Bem, D. J. (1972). Self-Perception Theory. In L. Berkowitz (Ed.), Advances in Experimental Social Psychology, Vol. 6, pp. 1-62. New York: Academic Press.

Cialdini, R. B, Reno, R. R., \& Kallgren, C. A. (1990). A focus theory of normative conduct: Recycling the concept of norms to reduce littering in public places. Journal of Personality and Social Psychology, 58, pp. 1015-1026

Dolan, P., Hallsworth, M., Halpern, D., King, D. and Vlaev, I. (2010). MINDSPACE: Influencing Behavior Through Public Policy. Cabinet Office: London.

Gardner, G. T., \& Stern, P. C. (2002). Environmental problems and human behavior (2nd edition). Boston, MA: Pearson Custom Publishing.

Gatersleben, B., Steg, L., Vlek, C. 2002. Measurement and determinants of environmentally significant consumer behaviour. Environment and Behavior, 34 (3), pp. 335-362.

Geller, E. S. (2002). The challenge of increasing proenvironmental behavior. In R. B. Bechtel \& A. Churchman, Handbook of environmental psychology . pp. 525-540, New York: Wiley.

Gifford, R. (2007). Environmental psychology: Principles and practice (4th Ed.). Colville, WA: Optimal Books.

Goldstein, N. J., Cialdini, R. B., \& Griskevicius, V. (2008). A room with a viewpoint: Using social norms to motivate environmental conservation in hotels. Journal of Consumer Research, 35, pp. 472-482.

Heath, Y., \& Gifford, R. (2002). Extending the theory of planned behaviour: Predicting the use of public transportation. Journal of Applied Social Psychology, 32, pp. 2154-2185.

House of Lords (2011), Behaviour Change, The House of Lords, pp. 111.

Hunt Allcott Social norms and energy conservation Journal of Public Economics, 2011, vol. 95, issue 9-10, pages 1082-1095 
Linda Steg, Charles Vlek, "Encouraging pro-environmental behavior: An integrative review and research agenda", Journal of Environmental Psychology · September 2009

Lindenberg, S., \& Steg, L. (2007). Normative, gain and hedonic goal-frames guiding environmental behavior. Journal of Social Issues, 63 (1), pp. 117-137.

MarktOnderzoekAssociatie (Developments in marketing research. Yearbook 2005), pp. 165-180. Haarlem (NL): De Vrieseborch.

Richard H. Thaler, Prof. Cass R. Sunstein-Nudge_Improving Decisions About Health, Wealth, and Happiness-Yale University Press (2008)

Russell, J. and Snodgrass, J. (1987) "Emotion and Environment" in D Stokols and I. Altman (eds) Handbook of environmental psychology. Ch. 8, pp245-281, New York: Wiley.

Schuitema, G., \& Steg, L. (2005). Perception of energy use of domestic appliances, 10, pp. 221279. New York: Academic Press.

Steg, L., \& Vlek, C. (2009). Encouraging pro-environmental behavior: An integrative review and research agenda. Journal of Environmental Psychology, 29, pp. 309-317.

Stern, P. C. (2000). Toward a coherent theory of environmentally significant behavior. Journal of Social Issues, 56(3), pp. 407-424.

Thaler, R.H., Sunstein, C.R. (2009) Nudge, improving decisions about health, wealth and happiness. Penguin Books: London

Thomas A. Heberlein. Navigating Environmental Attitudes Oxford University Press; 1 edition. September 24, 2012, Page 52 